REARRANGING THE FAMILY?

INCOME SUPPORT AND ELDERLY LIVING ARRANGEMENTS

IN A LOW INCOME COUNTRY

Eric Edmonds

Kristin Mammen

Douglas L. Miller

Working Paper 10306 
NBER WORKING PAPER SERIES

\title{
REARRANGING THE FAMILY? \\ INCOME SUPPORT AND ELDERLY LIVING ARRANGEMENTS IN A LOW INCOME COUNTRY
}

\author{
Eric Edmonds \\ Kristin Mammen \\ Douglas L. Miller \\ Working Paper 10306 \\ http://www.nber.org/papers/w10306
NATIONAL BUREAU OF ECONOMIC RESEARCH
1050 Massachusetts Avenue
Cambridge, MA 02138
February 2004

The authors wish to thank Kristin Butcher, Anne Case, Angus Deaton, Nina Pavcnik, Dori Posel, Duncan Thomas, Martin Wittenberg, NEUDC participants, and participants in the UC-Berkeley Development seminar for their helpful comments. Correspondence to Eric Edmonds, 6106 Rockefeller Hall, Department of Economics, Dartmouth College, Hanover NH 03755 USA, eedmonds@dartmouth.edu. The views expressed herein are those of the authors and not necessarily those of the National Bureau of Economic Research.

(C2004 by Eric Edmonds, Kristin Mammen, and Douglas L. Miller. All rights reserved. Short sections of text, not to exceed two paragraphs, may be quoted without explicit permission provided that full credit, including (C) notice, is given to the source. 
Rearranging the Family? Income Support and Elderly Living Arrangements in a Low Income Country

Eric Edmonds, Kristin Mammen, and Douglas L. Miller

NBER Working Paper No. 10306

February 2004

JEL No. J12, H55, I38, O15

\section{$\underline{\text { ABSTRACT }}$}

Despite the importance of living arrangements for well-being and production, the effect of changes in household income on living arrangements is not well understood. This study overcomes the identification problems that have limited the study of the link between income and living arrangements by exploiting a discontinuity in the benefit formula for the social pension in South Africa. In contrast to the findings of the existing literature from wealthier populations, we find no evidence that pension income is used to maintain the independence of black elders in South Africa. Rather, potential beneficiaries alter their household structure. Prime working age women depart, and we observe an increase in children under 5 and young women of child-bearing age. These shifts in co-residence patterns are consistent with a setting where prime age women have comparative advantage in work away from extended family relative to younger women. The additional income from old age support may induce a change in living arrangements to exploit this advantage.

Eric Edmonds

Department of Economics Dartmouth College

6106 Rockefeller Hall

Hanover, NH 03755

and NBER

eedmonds@dartmouth.edu

Kristin Mammen

Department of Economics

Barnard College

Columbia University

kmm13@columbia.edu
Douglas L. Miller

Department of Economics

University of California, Davis

dlmiller@ucdavis.edu 


\section{Introduction}

In this paper we study the impact of pension income on living arrangements in the context of a low income country. ${ }^{1}$ An evaluation of the effect of pension income on living arrangements is particularly timely given the rapid aging of the population in low income countries. The aggregate growth rate of elderly in low income countries is more than double that of wealthy countries, and as a result, many countries are considering adopting or expanding pension programs (Kinsella and Velkoff 2001). Living arrangements are of interest to economists because they are an important component of well-being. The U.S. literature on pensions and living arrangements emphasizes the consumption element of living arrangements (Costa 1997 and 1999, Englehardt, Gruber, and Perry 2002). People care directly about with whom they live, and living arrangements affect each person's ability to influence household decisions. In addition, living arrangements can affect the organization of household production (Benjamin 1992). This issue may be particularly relevant in the developing country context, but has not received much attention in the existing literature. ${ }^{2}$ Finally, the effect of pension income on living arrangements is relevant to the broader literature analyzing household responses to fluctuations in income such as the literatures on labor supply, consumption insurance, intrahousehold allocation, and the permanent income hypothesis. While many authors note concerns about potential biases attributable to endogenous living arrangements, little evidence exists documenting how significant these biases may be. ${ }^{3}$

\footnotetext{
${ }^{1}$ We use the phrases "living arrangements" and "household composition" interchangeably. Strauss and Thomas (1995) point to a large literature documenting that the concept of the household extends beyond a residential unit. We study the impact of pension income on the demographic traits of individuals that occupy the same physical residence as the elder.

${ }^{2}$ Living arrangements may also affect how the household copes with risk and how household decisions are made. These issues are discussed in section 2 .

${ }^{3}$ We are aware of the following studies that consider changes in household composition with income changes in a developing country context. Ainsworth (1996) considers the determinants of child-fostering in Cote d'Ivoire and finds that the receiving family's demand for labor is highly correlated with the level of fostering. Butcher (1993)
} 
The paucity of evidence on the link between pensions or income more generally on living arrangements is driven by three main empirical challenges. First, household decisions that impact income are made by those living in the household; changing household members may change these decisions. This creates the problem of disentangling the effect of income on living arrangements from the effect of living arrangements on income. Second, income varies over the life cycle, and pension income in particular is age dependent. Living arrangements change over the life cycle as well. Disentangling the impacts of pension income from the impacts of aging is challenging. Third, income (especially pension income) depends on cumulative work histories. Thus, income today depends on decisions made earlier, and these decisions may also independently influence today's living arrangements.

In this paper we study the impact of an old-age income support program on the living arrangements of elder, black women in South Africa. This is a good context for considering the impact of income on household composition, because the unique benefit structure of the South African social pension enables us to address the identification problems that have limited research on the effects of income on living arrangements. For elder black women in South Africa, social pension income depends primarily on age-eligibility - women become eligible for the pension at age $60 .{ }^{4}$ Thus, pension income does not depend on the presence of extended families nor cumulative work histories. We identify the impacts of pension income on elderly living arrangements, overcoming the problem that pension income is age dependent, by

uses the same dataset as Ainsworth and finds that changes in child fostering and the number of adults are highly correlated with changes in household economic status. Grimard (2000), also using data from Cote d'Ivoire, finds an association between rainfall, income, and household composition, although he posits that changes in household composition are driven by labor demand. Frankenberg, Smith, and Thomas (2003) find that Indonesia's financial crisis induced a movement of dependents and some types of workers from high cost urban areas to lower cost rural areas.

${ }^{4}$ There is a means-test to the social pension, but it is set at such a high level that it does not bind for most black households (Alderman 1999). For this reason we focus on blacks. For other groups in South Africa, pension eligibility is more likely to be an endogenous decision. 
exploiting the discontinuous nature of the age eligibility rule in the pension benefit formula. We assume that absent the pension, changes in living arrangements associated with the aging of black women are smooth. ${ }^{5}$ We then look for discontinuous changes in composition that occur at the age of pension eligibility, allowing for flexible smooth trends in age.

Our results differ from the previous literature in several interesting ways. In particular, the existing literature on pensions and living arrangements (which is primarily set within developed countries) focuses on how pensions enable the elderly to maintain their independence (Costa 1997 and 1999, Carvalho 2000, McGarry and Schoeni 2000, Englehardt, Gruber, and Perry 2002). There is nearly universal empirical support for the hypothesis that income enables the elderly to maintain their preferred state of independence. We examine the effects of pension age-eligibility on the household size of the elderly, as well as the probability that they live alone, or only with a spouse. In contrast to much of the previous literature, we find no increase in independence associated with pension eligibility.

However, we do uncover several interesting changes in living arrangements associated with pension receipt. First, we find an increase in the number of children aged 0-5 present when an elder woman becomes pension eligible. Second, we find an increase in the number of women aged 18-23 - about the right age to be the children's mothers. Third, we find a decrease in the number of women aged 30-39. The magnitudes of these responses are meaningful - with changes of approximately $10 \%$ of the base age-specific population numbers. We suspect that women 18-23 and women 30-39 are good substitutes in household production, but that women 30-39 have an advantage in work away from home, perhaps because the child care obligations of young mothers make them less productive in the market or less able to live away from home.

\footnotetext{
${ }^{5}$ We focus on women because we believe our smoothness assumption is more tenable for women than men, for reasons discussed in Section 3.
} 
Moreover, the grandmother may help with the child care of young children, thereby improving the ability of young mothers to work in addition to their household production activities.

In the next section, we review the role living arrangements play in household decisions and why they may be affected by pension income. In section 3, we describe the South African pension program in greater detail in the context of our identification strategy. Section 4 presents our findings from the 1996 South African population and housing census and discusses other possible interpretations. Section 5 concludes by summarizing our findings and discussing their implications for researchers evaluating the effects of pensions (or income more generally) on various household attributes.

\section{Income and Living Arrangements - Theoretical Background}

We use the term "household" to refer to a set of co-resident individuals and the term "family" to refer to the broader kin network, many of whom may not live together. In this section, we consider why a change in the income of an individual family member may influence household living arrangements. We classify possible explanations into three broad categories: consumption, contracts, and production.

\subsection{Household composition as consumption}

Most previous studies of the effects of income on living arrangements view these arrangements as something that individuals have preferences over, and argue that additional income increases consumption of more preferred living arrangements. Individuals may prefer children or certain family members more than others, but most authors emphasize independence as the preferred living state (Michael, Fuchs, and Scott (1980), Costa (1997), Costa (1999), Carvalho (2000), McGarry and Schoeni (2000), and Englehardt, Gruber, and Perry (2002)). When living arrangements are viewed as consumption, differences in household composition 
associated with variation in income are interpreted as revealing preferences over living arrangements.

In collective decision making models (Bourguignon and Chiappori 1992), additional income in the hands of an individual may increase their influence on the allocation of family resources (Lundberg and Pollak 1993). In this way, additional income to an elder may then increase her influence in her family's affairs. This rising power may affect the desirability of some living arrangements. Alternatively, she may use her power to change her living arrangements by choosing preferred household members or living environments. Thus, as within a unitary household model, changes in household composition associated with variation in income can be viewed as indicative of the elder's preferences over living arrangements.

\subsection{Household composition and intra-familial (informal) contracts}

Increased income may change the informal contracts that families engage in, and can subsequently affect household composition. For instance, if family members insure each other's consumption against uncertain dates of death (Kotlikoff and Spivak (1981)), or uncertain income shocks (Rosenzweig (1988)), then an increase in income may induce a change in these contracts. Moreover, geographic diversification may be an important part of intra-familial insurance strategies (Rosenzweig and Stark (1989). Thus, an increase in income may alter the types of diversification strategies that are optimal. For example, Butcher (1993) emphasizes that child fostering may be a mechanism through which families smooth fluctuations in resources.

In addition, household composition may be a direct factor in the enforcement of intrafamilial contracts. Suppose, for instance, that the elderly wish to transfer resources to their grandchildren, but are unable to monitor their adult children's compliance with these wishes. In this case, they may choose to have the grandchildren come live with them. Alternatively, if the 
family's contract calls for the elderly to share their pension income with their families, but this sharing cannot be enforced when the family members live apart, we may see an increase in cohabitation. The change in household composition in this case (as with the case of the children mentioned above) does not arise from preferences over living arrangements per se. Instead, it arises because household composition is an important input to enforcing intra-familial contracts.

\subsection{Household composition and production}

On the production side, additional income may enable the elderly to purchase market substitutes for goods or services otherwise provided by household members (Hoerger, Picone, and Sloan 1996 examine substitution between market care and family care of the elderly in the US context). Alternatively, additional income may overcome credit constraints which prevent the family from making efficient changes to how it arranges production. The pension income may enable an elderly household to take in grown children or grandchildren to provide nontradable goods or services that improve the well being of their family. ${ }^{6}$ Similarly, movements to exploit earnings opportunities and to minimize living costs have been shown by Frankenberg, Smith, and Thomas (2003) to be important coping mechanisms for the shock of the Indonesian financial crisis.

To summarize, the theoretical literature offers a wide variety of ways in which additional income may impact the living arrangements of the elderly, and there are not clear predictions in the theory about which mechanisms should dominate. Given the range of possible impacts, the effect of additional resources on household composition is ultimately an empirical question.

\footnotetext{
${ }^{6}$ In data from the Cote d'Ivoire, Ainsworth (1996) finds that the receiving family's demand for child labor is an important determinant of the child fostering decision (even more so than the level of the sending family's resources), and Grimard (2000) finds that labor demand is a driving force for changes in labor demand among adults as well.
} 


\section{Identification}

Empirical examination of the effects of old age support on the living arrangements of the elderly poses several challenges, because support generally depends on a recipient's cumulative labor history, household composition, and life-cycle attributes. Several unique attributes of South Africa's Old Age Pension Program in South Africa's black population make it well suited for considering the effect of old age support on elderly living arrangements.

The uniqueness of the South African program stems from its origin. At the end of apartheid the white social pension was extended to the black population. Blacks are substantially poorer than whites in South Africa, and so the maximum pension benefit for a black South African is approximately twice the median per capita monthly household income of blacks (Case and Deaton 1998). There is a means test to the pension, but it is set as such a high level that it does not exclude most black South Africans (Alderman 1999). Moreover, the means test does not take in to account the income of family members, so there is no incentive to rearrange households in order to be eligible for the pension (as many have argued exists for social transfer systems such as Aid to Families with Dependent Children in the United States, e.g. Bishop 1980). Thus, the determining factor for pension eligibility is age rather than labor histories or household composition. Women become eligible for the pension at age $60 .^{7}$

Our empirical approach is driven by this age-discontinuity in the benefit structure of the social pension. Our approach is to compare living arrangements just before pension eligibility to living arrangements immediately after; thus, pension eligible individuals are older than their noneligible counterparts. If there is any trend in household composition with respect to age, simple eligible/ineligible comparisons will confound the impact of the pension with the impact of age. To allow for age trends, we follow Porter (2000) and (in a nonparametric fashion) model the

\footnotetext{
${ }^{7}$ See Case and Deaton 1998 and van der Berg 2001 Chapter 4 for further details.
} 
smooth age trend in living arrangements. Our estimate of the effect of pension eligibility on living arrangements comes from measuring any discontinuous changes in living arrangements at the age of pension eligibility.

Specifically, the living arrangements variable, y, for a woman of age $a$ depends on resources and characteristics of the household and all of its potential members. We assume the effects of these (unobserved) resources and characteristics on living arrangements are smooth with respect to an individual's age. We write the expectation of the outcome variable $y$ conditional on age as:

$$
y=m(a)+d \alpha+\varepsilon
$$

where $d$ is an indicator that is 1 if a person is pension eligible, $E[\varepsilon \mid A]=0$ (where $a=A$ is the age of pension eligibility), and $m\left(\right.$ ) is continuous at the age of pension eligibility. ${ }^{8}$ Porter suggests rewriting (1) as:

$$
(y-d \alpha)=m(A)+\varepsilon .
$$

We have a new dependent variable: $(y-d \alpha) . \alpha$ is estimated by finding a value of $\alpha$ that minimizes the averaged squared deviation between this new dependent variable and the nonparametric estimate of $m(A)$. Thus, we use data from both above and below the discontinuity in pension eligibility at age 60 in a kernel regression, with more weight given to

\footnotetext{
${ }^{8}$ In the data, observed age is discrete. In a set of Monte Carlo experiments where the generated data has moments that match those in the observed data, we have compared results when age is observed continuously to results when age is rounded down to the nearest integer. We find that both the continuous results and the results where age is rounded down to an integer have similar distributions of estimated treatment impacts and t-statistics with approximately normal distributions.
} 
data points closest to age 60 , to estimate the change in the conditional expectation of the living arrangements variable at the age when an individual becomes pension eligible. ${ }^{9}$

Two assumptions are critical for the consistency of this regression discontinuity estimator and deserve special emphasis. The first is that the probability of treatment (pension eligibility) varies discontinuously at the age cut-off point. This assumption follows directly from the pension benefit formula, and we will show that the data are consistent with this assumption. The second assumption is that if there were no treatment (i.e., no pension program), the outcome of interest would be continuous at the age cut-off. That is, while we expect that a given household characteristic (number of small children in the household, for example) may vary with the age of the oldest woman, there is no a priori reason to think that at age 60 (and not at 59 or 61) household characteristics should change dramatically. Retirement that would occur even in the absence of the pension program is one possible concern. However, the data do not suggest that retirement is a substantive issue for women (this issue is discussed in Appendix A).

One important qualification to this discontinuity approach is that we are limited in the types of household changes it can detect. For example, we cannot identify effects that occur if households respond to the pension either before or after actual eligibility. If pension receipt tends to cause relatives to move in with an elder woman, they may do so when she turns 59 , in anticipation of her becoming eligible. Alternatively, it may take several years for household

\footnotetext{
${ }^{9}$ In our kernel estimation, we use an Epanechnikov kernel (specifically: $K(z)=(.75)\left(1-.2 z^{2}\right) / \sqrt{5}$ for $|z|<\sqrt{5}$ ), and a bandwidth of 2. Standard errors are calculated following the discussion in Porter (2000). For reference of future researchers interested in using the Porter regression-discontinuity methodology, the constant $c_{k}$ in Theorem 1 (Porter 2000, pg. 12) is 6.3582 for the indicated form of the Epanechnikov kernel.

Our choice of bandwidth is driven by a desire to balance identifying locally against the need for smoothing to account for age trends and to prevent us from identifying off of idiosyncratic bumps in the data. We have compared the findings presented below to what we would find with alternate bandwidths of 1.5 and 3 . We reach qualitatively the same conclusions with either alternative bandwidth. The main exception to this is that with the bandwidth equal to 3 , the coefficient on children 0-5 is not significantly different from zero. We cannot reject statistically that our results for bandwidths 1.5 or 3 are the same as the point estimates using a bandwidth of 2 in every result highlighted below with the exception of the income results where a bandwidth of 3 returns a 17 percentage point decline in the probability that a woman reports no income with pension eligibility.
} 
members to adjust their composition in response to pension eligibility. Both of these timing issues attenuate any measured program impact. We note, however, that Lund (1993) finds no descriptive evidence of individuals being able to borrow in advance of pension eligibility even though pensioners have better access to credit once they have attained eligibility. Hence liquidity constraints may restrict the ability of individuals to act in anticipation of the pension.

A second issue is that we focus on age-eligibility rather than actual pension receipt. We do so because pension take-up is an endogenous household choice whereas an individual's age is not. Our estimates are an attenuated measure of the true impact if take-up of the pension is incomplete (as it certainly is) or does not coincide exactly with eligibility. Moreover, there is apt to be measurement error in reported ages. If this measurement error is classical, it will further attenuate our findings based on age-eligibility. In practice, there appears to be a moderate degree of rounding in reported ages in the data to either ages in round decades or to ages that correspond to birth years reported in round decades. ${ }^{10}$ This creates a problem for identification, because the pension eligibility of women begins at age 60 . In the presentations of the raw data below, it will be obvious that women at age 60 generally look different than would be predicted by the trend prior to age 60 and the trend after age 60 (see especially Figures 1,2,4, and 5). Thus, we exclude women at age 60 from estimation. ${ }^{11}$ This alters the population to which our results are

\footnotetext{
${ }^{10}$ In a set of Monte Carlo simulations, we have generated data with a continuous age distribution and with heaped ages that correspond to what we observe in the data used in this study. Using the regression discontinuity design described in this section, we found that estimated treatment effects were more disperse with heaped data. However, the distributions of the T-statistics were approximately standard normal in both generated datasets. Thus, statistical inference is not adversely impacted by age heaping per se.

${ }^{11}$ In the simulations described in the previous footnote, we observed that when we excluded observations at age 60 from the heaped data, the standard deviation of the distribution of T-statistics increased by roughly 30-50 percent. As a check on our results, we have used a bootstrapping procedure to generate empirical standard errors for each of our models. In simulations, bootstrapped standard errors generated T-statistics that were approximately standard normal. In our data, bootstrapping increases estimated standard errors by approximately 45 percent. The statistical significance of our results is generally unaffected by using bootstrapped standard errors. The only exception to this in the main results (presented in the next section) is that the findings for children $0-5$ are only significant at 10 percent $(\mathrm{T}=1.92)$.
} 
applicable. That is, our estimated impacts are most relevant for the population that is less likely to misreport its age.

\section{Data and Main Findings}

\subsection{Data}

While the identification assumptions in our empirical work are weak, the methodology requires a large dataset for our analysis to have statistical power. As a result, we focus on the living arrangements of black elder women in black headed households in the 10 percent public use sample of the 1996 Population and Housing Census of South Africa. ${ }^{12}$ Households are defined in the census as a group of people (or one person) who live together at least 4 days a week and jointly provide themselves with food and other necessities. Live-in employees were regarded as separate households (Statistics South Africa. n.d. (c)). ${ }^{13}$ Our analysis is then based on the 299,885 (unweighted) black women 40 and older living in households with black heads. ${ }^{14}$

We focus exclusively on women in this paper, because we are concerned that our identification assumptions are more suspect for men. First, we are more comfortable with our assumption that the underlying age trends in our measures of household composition are smooth absent the pension for women. Men are more likely to face retirement incentives (absent the pension) at the age of pension eligibility in the formal sector of the South African economy. As

\footnotetext{
${ }^{12}$ Statistics South Africa (Stats SA) administered the 1996 census to cover the night of October $9^{\text {th }}$ to $10^{\text {th }}$. Respondents either filled in the questionnaires themselves or were interviewed by enumerators. Questionnaires were translated into all 11 official languages of South Africa. Data were adjusted for undercount (with both household and person weights) on the basis of a nationwide post-enumeration survey. (Statistics South Africa. n.d. (a)) The data we use come from a 10 percent public use sample representing 40,578,900 individuals and 9,058,540 households. Individuals not living in households but in hostels or institutions such as prisons and hospitals were counted in the census but are excluded from our analysis (Statistics South Africa. n.d. (b)).

${ }^{13}$ We designate black households by the race of the household head. In a small percentage of cases where no head of household was indicated, we designated a black household by the race of the next most closely related family member (usually the spouse). The census allowed more than one household head to be reported; for the 0.4 percent of households with multiple heads we chose the oldest head for determining the race of the household (in the instance of a tie for oldest, we chose the oldest male)

${ }^{14} 3$ percent of the sample is dropped because age information is missing for one or more household members. We dropped 62 individuals in households with at least one member indicating institutional residence (this being inconsistent with our sample definition).
} 
discussed in appendix A, the data do not suggest that formal retirement is a significant issue for women. Second, Bertrand, Mullainathan, and Miller (2003) report that in some provinces men report pension take up upon turning 60 , rather than 65 . Thus, our assumption that treatment is discontinuous at the age of pension eligibility may not be fully accurate in the male population. Moreover, in addition to these identification concerns, much of the previous literature on the South African pension program (Duflo 2003, Bertrand, Mullainathan, and Miller 2003, for example) has concluded that female pensioners are more likely to share their pension income with household members. Thus, we are more likely to find program effects in the female population.

Table 1 presents means and standard deviations for the living arrangements of women within 10 years of pension eligibility. Column 1 contains summary statistics for women that are not yet pension eligible, and column 2 refers to eligible women. Individuals who are pension eligible live in slightly larger households. There are more young children ages 0 to 5 in households with a pension eligible individual. There are fewer individuals aged 18-23 living with the older women. In addition, we observe more persons of prime work age (30-39) in pension eligible households.

This naive comparison of households with and without a pension eligible person does not reflect the causal impact of the pension program, because age trends are confounded with the pension program. The differences in household structure found in table 1 may be due entirely to age and have nothing to do with the pension per se. This problem of separating age differences from the effect of the pension benefit is the reason for using the regression discontinuity estimator applied in the next section. 


\subsection{Pension Eligibility Affects Income}

Our focus is on how living arrangements change discontinuously at the age of pension eligibility. Although we do not attempt to directly measure an income elasticity of living arrangements, we interpret the changes in living arrangements associated with pension eligibility as an effect of pension income. Figure 1 presents some support for the idea that pension eligibility substantially impacts income. Figure 1 also illustrates how our empirical approach works in practice.

The Census asks for each household member's income, with possible responses grouped into 14 categories. In panel A of figure 1, we plot the probability that a woman reports receiving zero income against her age. The circles in panel A are (unsmoothed) nationally representative means from the census, and 95 percent confidence bounds for these means are also graphed. The curve is the result of using our semi-parametric regression discontinuity estimator. We regress an indicator that is 1 if a woman reports no earnings in the last year against age, allowing a change (as described above) at age 60 when a woman becomes pension eligible. Panel A shows that about 58 percent of women in their early 50's report zero income during the previous year. This proportion declines slightly among women in their late 50's, and drops dramatically - 12.5 percentage points - as women become age-eligible for the pension. The T-statistic for the null hypothesis that the jump at age 60 is zero is over $15{ }^{15}$ In panel B we consider the probability that a pension-eligible black woman reports a personal income that is equal to or greater than the amount of the pension. This probability increases by 12 percentage points at age 60 , a statistically significant increase. Thus, we treat the effects of age eligibility as income effects throughout this study.

\footnotetext{
${ }^{15}$ This estimate (as well as most estimates that follow in the paper) is based on 53,834 individuals receiving nonzero weight. For readers who wish to compute hypothesis testing using a Schwarz (or Bayesian Information)-type Criterion, we calculate that $\operatorname{sqrt}(\log (53,834))=3.3$ could be used as an alternate critical value to the usual 1.96 .
} 


\subsection{Pensions do not alter the trend away from independence}

We have noted that most of the existing literature on elderly living arrangements in high income countries finds that additional income enables the elderly to continue their independence. ${ }^{16}$ We begin examining whether pension eligibility affects elderly independence in South Africa by considering whether there are changes in household size around the elderly with pension eligibility. In Figure 2 we plot household size against a woman's age; as before, the circles represent the weighted, unsmoothed census means, and 95 percent confidence bounds for these means are pictured. The regression curve shows a general trend towards increasing household size as women approach the age pension eligibility. This upward trend in household size with age may reflect that older individuals are less able to rely on their own earnings and physical output or that older individuals will have older children who are thereby more likely to have children or even grandchildren of their own. Our discontinuity approach captures any discrete changes associated with pension eligibility in this trend towards increasing household size.

The point estimates of the size of the discontinuity are reproduced in table 2 , row 1 . We find an increase of approximately 0.09 household members associated with pension eligibility. This corresponds to an approximate 1 percent increase in household size. ${ }^{17}$ This small increase in household size is not statistically significant at conventional levels.

We also examine directly the effects of pension eligibility on the probability that an elder woman lives independently - either alone or only with a spouse. In Figure 3 the dependent

\footnotetext{
${ }^{16}$ For examples, see Michael, Fuchs, and Scott (1980), Borsch-Supan, McFadden, and Schnabel (1993), Costa (1997), Costa (1999), and Engelhardt, Gruber, and Perry (2002). For middle income countries, DaVanzo and Chan (1994) and Carvalho (2000) find similar results for Malaysia and Brazil.

${ }^{17}$ In order to calculate percentage changes, we need to know what the mean household size (or any other dependent variable) would be at the age of pension eligibility in the absence of the pension program. To calculate this, we use the age trend before pension age to project the expected household size at the pension age. These projected means are the means reported in tables 2 and 3 and referenced henceforth in the text.
} 
variable is an indicator that is one if woman lives alone or only with a spouse. We see that living independently is rare among elder South Africans- only 8 percent of women age 59 do so. In addition, there is a general trend away from living independently as a black woman ages. Figure 3 shows there is no statistically significant break in this trend associated with pension eligibility. Estimates of $\alpha$, the pension eligibility associated change in the probability an individual lives alone or with only a spouse, are in table 2 , rows 2 and 3 . These coefficients are small and statistically insignificant. Thus, the data fail to reject the hypothesis of no impact of pension eligibility on elderly independence. This finding contrasts with almost all of the research on pension effects on living arrangements from populations richer than black South Africa.

There are a number of possible explanations for why the results on elderly independence are different in South Africa. First, the preferences of the elderly over independence could be different in South Africa. However, we do not have strong priors that elderly South Africans care more about their extended family or have more desire to live with kin than do elders elsewhere. Second, there may be little scope for pension income to affect independence (even if the elderly would prefer it) given that an independent arrangement is rare. A third possibility is that the pension in South Africa could be so large that (due to the absence of complete contracts) adult children merge households with the elderly to monitor the sharing of the funds, inducing a decline in elderly independence. However, our results do not suggest a decline in independence with the pension. Rather, the general age trend away from independence continues unabated with the pension eligibility.

Another explanation for the lack of increased independence is that there may be missing markets in South Africa for goods and services that would enable the elderly to compensate for the diminishing capacity for home production that accompanies age. Alternatively, these goods 
and services may be available, but substantially more expensive than using within household labor to provide them. In this case, pension income may be used by elders to alter household composition in order to either bring in additional labor to provide these goods and services. Finally, liquidity constraints could also be relevant. With liquidity constraints, an increase in income could lead a decline in the cost of home production by a reorganization of production (either through purchased inputs or changes in the labor mix). Thus, to the extent that household production is more significant in low income countries because of missing markets or because of labor market imperfections, the effect of income on shadow prices may be more important. In this way, incomplete or underdeveloped markets for goods and services consumed by the elderly might be an important reason why we do not observe income effects on independence for black South Africans.

\subsection{Pensions are associated with increases in the number of young children and women of} age to be their mothers as well as a decline in the presence of prime working age women

Though we observe no break in the trend away from independent living and no statistically significant changes in household size, the discussion of why household composition may change with income suggests scope for important changes in living arrangements when women become pension eligible. We examine changes in living arrangements by looking at changes in the presence of females and males for various age groupings in Appendix B. This section highlights the most important of these results. Figures 4-6 contain the census means and kernel regression results by the age of the elder woman for the number of children ages 0 to 5 (figure 4), the number of women ages $18-23$ (figure 5), and the number of women ages $30-39$ (figure 6). These graphs show the basic elements of how the households of pension-eligible women are re-shaped. The regression discontinuity estimates of the impacts are reproduced in 
Table 3. One obvious question is whether the findings in figures 4-6 represent the movement of the elderly or the movement of others. The discussion in Appendix C suggests that all of our main findings are present in the sub-sample of elders who live in rural areas and have not moved in the last 7 years. ${ }^{18}$

We find a large and statistically significant increase of 0.05 in children $0-5$ with pension eligibility. This corresponds to a 7 percent increase in the number of young children in a household on average. This increase in the number of young children does not appear to be an effect of the pension on fertility that is timed with pension eligibility. We examine whether the pension is associated with an increase in births in the household. In Table 3, row 4, we do not find any statistically significant relationship between births in the year prior to pension eligibility and female pension receipt. The estimated change in fertility with the pension eligibility of women is actually slightly negative. Of course, our method does not capture the effect of anticipated pension income on fertility. Hence, the results in figure 4 reflect either children being brought into the household or fertility in anticipation of the pension by more than a year.

We observe an increase in the presence of young women ages 18-23 of .04 young women per elder. This corresponds to more than a 10 percent increase in the presence of young women. The rise in young children and 18-23 year old women may be related, because it is not unusual for a black woman in the 18-23 year old group to have a child, and that child is likely to be aged 5 or younger. ${ }^{19}$

\footnotetext{
${ }^{18}$ The point estimates are very similar for most variables when we condition on rural non-movers. However, statistical significance for impacts on children 0-5 and women 18-23 are not robust to using the bootstrapped standard errors discussed in footnote 11.

${ }^{19}$ Age-specific fertility rates for black South African women ages 20-24 are estimated to be from 0.104 to 0.159 (Moultrie and Timaeus, 2002). The relationship identifiers in our data do not permit the matching of individual children to their mothers. Frankenberg, Smith, and Thomas (2003) also find evidence of the co-movement of young children and women who are probably their mothers during Indonesia's financial crisis.
} 
At first glance, a comparison of figures 4 and 5 might seem inconsistent with a relationship between the increased cohabitation of women 18-23 and children 0-5. Rather, they illustrate the usefulness of our regression discontinuity approach. If a researcher were to look only at the age trends in these variables (figures 4 and 5), she would note that the number of children increases with the elder's age, and the number of young women decreases with the elder's age. By focusing on the age trends alone, she might conclude that these two variables move in opposite directions. This conclusion is reinforced by comparing the means in Table 1. However, our discontinuity estimator uncovers a different pattern that we think is more likely to be related to exogenous changes in income. With pension eligibility, there is a large increase in women 18-23 even though there is a decreasing trend in number of young women in the household. With this discontinuous increase in young women at the start of their child-bearing years, we also observe a large change in the number of children 0-5 in the household.

The data also reveal a decline in women age 30-39 that is of a similar magnitude to the increase in young women. That is, 0.04 women 30-39 depart and 0.04 women 18-23 arrive with pension eligibility. As with young women, the change in the presence of 30-39 associated with pension eligibility is opposite in direction to the overall age trend in the presence of women 3039. As such, it is an effect of pension eligibility that would be missed without focusing on the discontinuity in the pension eligibility rules.

Why do we observe an increase in the number of children and young women with pension eligibility? An obvious potential reason is the direct consumption of child companionship by the elderly. Elders may consume more child companionship with an increase in income if child companionship is a normal good or they may prefer to live with small children and the additional income strengthens their influence on consumption choices. A number of 
studies have found that increases in income are associated with increased decision-making power of the income recipient (e.g. Lundberg, Pollak, and Wales 1997, Thomas and Rubalcava 2001). Additionally, the increase in children and young women may be due to a change in how the family organizes its production. Children may accompany parents moving back to the household of the pensioner; or they may arrive unaccompanied, because the pensioner is taking care of them while the parents work. In this latter case, the rise in women at the start of their childbearing years would be purely coincident.

It is interesting to note that the entrance of young women is similar in magnitude to the decline in the presence of prime working age women. Is there an explanation for this pattern that does not depend on preferences or changes in intrahousehold influence? These results are not necessarily consistent with the idea that "predators" are moving in to co-opt the income of elders or that living arrangements are changing to monitor elderly management of the cash, if prime age workers (rather than young mothers) are most effective at this sort of behavior. Rather, we speculate that young mothers and older women are similarly productive in home production but that young women have a lower relative value of market time than prime age women. This may be because they have accumulated less work experience and because there are complementarities in raising young children and working at home. ${ }^{20}$ Thus, the elder uses the pension income to shift towards the relatively low cost input into household production. This appears in the data as an outflow prime age working women and an inflow of young mothers. The comparative advantage of prime age women in work away from home may stem from the fact that they have older children that do not require continual supervision. Hence, the help of a grandmother is not

\footnotetext{
${ }^{20}$ Differences in the relative value of time between older women and younger mothers may also interplay with household risk management strategies. For example, when the pension provides a stable source of income at home, the prime age woman may be able to move to an employment opportunity where transfers back home are difficult to do quickly in response to a crisis, because she knows that the household will be able to use the pension income to cope with the short-term consequences of a shock.
} 
required to increase the mother's productivity. It is plausible that for younger women whose children need more care, the grandmother serves a caretaking role that helps improve the family's return on young mothers. We find this explanation plausible, although it cannot be distinguished from an explanation based on preferences.

\section{Conclusion}

In this paper we document the changes in living arrangements that result from pension eligibility for elderly black South African women. We do so using a regression discontinuity estimator that relies on weak assumptions to obtain the causal impacts of pension income on composition. In particular, we assume that the underlying age-composition relationship is smooth in age and that the probability of receiving the pension changes discontinuously at the age of pension eligibility. In this way, our study illustrates how administrative program rules can be a useful source of identification to circumvent the endogeneity problems that have limited the study of the relationship between income and household composition.

In contrast to much of the literature on wealthy countries, we find no evidence that the additional pension income leads to an increased propensity to live alone. Both the probability of independent living and the average size of the household do not change with pension eligibility. Our findings offer a counterexample to the notion that "[as the financial] status of elderly people improves, a larger proportion are able to afford to live alone and choose to do so in independent dwellings..." (Kinsella and Velkoff 2001, p. 68). Instead, our findings emphasize the role that the elderly play in supporting their extended families as well as the support the elderly in turn depend upon. One important reason for why this interdependence dominates the desire to live independently may be the less developed markets for many of the goods and services consumed by households in the South African context. 
Instead of using pension income to maintain their independence, elder women use their income to alter living arrangements. These adjustments take several forms. First, when a woman becomes pension eligible, we observe a decline in the number of co-resident women in their 30s, who may have a comparative advantage in work away (labor force participation rates peak for women in the census around age 40, and are high for women 30-50 years old). Second, we find increases in the presence of young children ( 0 to 5$)$ and of women whose age group suggests that they could be these children's mothers (18 to 23$)$. This is consistent with the caretaking role of grandmothers emphasized in some of the descriptive literature. Alternatively, missing markets and labor market imperfections in the developing country context may be responsible for this distinct result although we cannot rule our explanations that depend on preferences or changes in family decision-making. Young mothers may have comparative advantage (relative to older women) in working within the household and in the presence of elders both because of their significantly shorter work experience and because of the burdens and costs of rearing young children. The pension income then enables the household to allocate labor more optimally by moving young women in and prime-age women out.

The changes in living arrangements that we observe have several implications. First, there is a large literature documenting that grandparents help their grandchildren and hence that social policy directed at the elderly benefits other generations (e.g. Case 2003, Case and Deaton 1998, Duflo 2003, Edmonds 2003, Jensen 2004, Lund 1993). This paper highlights another mechanism by which elders may assist other generations: enabling individuals to move out of the household and others to move in.

Second, policy makers need to use caution in designing income transfer programs given the substantive changes in living arrangements observed with pension eligibility. In addition to 
the usual distortions imposed by government transfer programs, a policy that is conditioned on household composition may introduce additional distortions, by interfering with households' optimal responses to income changes. For example, targeting cash transfers to children but varying transfers with household size or limiting transfers to households with single parents may prevent individuals from adjusting their living arrangements in response to income fluctuations.

Third, the systematic changes in living arrangements in response to income changes highlight the fact that household members move in and out as a response to changes in income. This ability to shift living arrangements has implications for the consumption, insurance, growth, intrahousehold, and labor supply literatures that require further investigation.

We conclude with three examples of how our results might have implications for other studies evaluating the effects of a pension program or changes in household income. For example, there is a literature on whether targeting or labeling income affects how it is spent (Thaler 1990, Kooreman 2000, Edmonds 2002). In the context of the South African pension, Case and Deaton (1998) consider whether the marginal propensity to spend pension income is different than for other sources of income (they do not find it to be different). As they point out, the effects of the pension on living arrangements could temper their conclusions. Changes in household composition will change expenditure patterns directly. Therefore a different marginal propensity to spend out of pension income could reflect either the treatment of pension income or underlying changes in household composition if the marginal propensity to consume does not vary across types of income.

A second example applies to the literature that considers the effects of income increases on individual well-being. For example, Duflo $(2000,2003)$ finds that the Old Age Pension improves the nutritional status of co-resident children. Our study documents an inflow of 
children due to the pension. As Duflo (2003) notes, if this inflow is comprised of particularly health (or less healthy) children, then estimates of the impact of the pension on the health may be biased. For example, an altruistic grandmother might bring in relatively disadvantaged children to care for when she begins to receive the pension. This selection of disadvantaged grandchildren could cause estimates of the pension's impact on child nutrition to understate its true impact. Interestingly, Duflo $(2000,2003)$ finds an impact of the pension on the health of girls, but not boys. We find that the pension results in an inflow of boys more than girls. One possibility is that Duflo's "zero result" for boys may reflect a positive impact on health, combined with a negative selection effect in terms of household composition.

A third example relates to research that considers the impacts of government transfer programs on labor supply. In the South African context, Bertrand, Mullainathan, and Miller (2003) find declines in the labor supply of adult males associated with the pension receipt of elder women, but they do not observe declines in the labor supply of prime-age women. Our finding of substantive decreases in the number of prime-age women with female pension eligibility might imply that the absence of measured labor supply effects for women may be driven by an outflow of prime-age women, who would otherwise stop working in the presence of the pension. Naturally, as with the other examples, one could imagine other selection stories that generate different types of bias. However, in general it is critical to consider changes in household composition when evaluating response to changes in household income.

\section{References}

Ainsworth, M. (1996): "Economic Aspects of Child Fostering in Cote d'Ivoire," in Research in Population Economics, Volume 8, T. Paul Schultz editor. Greenwich, Ct: JAI Press, 1996. 
Alderman, H. (1999): "Safety Nets and Income Transfers in South Africa." World Bank Africa Region Discussion Paper 19335. February.

Becker, G. (1973): "A Theory of Marriage." Journal of Political Economy. 81: 813-846.

Benjamin, D. (1992): “Household Composition, Labor Markets, and Labor Demand: Testing for Separation in Agricultural Household Models," Econometrica, 60(2), 287-322.

Benjamin, D., Brandt L., and Fan J. Z. (2003): "Ceaseless Toil? Health and Labour Supply of the Elderly in Rural China," University of Toronto Manuscript.

Bertrand, M., S. Mullainathan, and D. Miller (2003): "Public Policy and Extended Families: Evidence from Pensions in South Africa." World Bank Economic Review, 17(1), 27-50.

Bishop, J (1980): "Jobs, Cash Transfers, and Marital Instability," Journal of Human Resources, 14, 301-34.

Borsch-Supan, A. (1989): “A Dynamic Analysis of Household Dissolution and Living Arrangement Transitions by Elderly Americans." NBER Working Paper \#2808. January.

Borsch-Supan, A., D. McFadden, and R. Schnabel (1993): "Living Arrangements: Health and Wealth Effects.” NBER Working Paper \#4398. July 1993.

Butcher, K. (1993): "Household Size, Changes in Household Size, and Household Responses to Economic Conditions: Evidence from the Cote d'Ivoire," Three Essays in Household Size, Resource Allocation, and Migration, Princeton University Ph.D. Dissertation, 1993.

Cameron, L., (2000): "The residency decision of elderly Indonesians: A nested logit analysis." Demography, 37(1), 17-27.

Cameron, L. and Cobb-Clark, D. (2001): "Old-Age Support in Developing Countries: Labor Supply, Intergenerational Transfers, and Living Arrangements." University of Melbourne Manuscript.

Carvalho Filho, I. E. (2000): "Elderly Women and Their Living Arrangements in Brazil," MIT Manuscript.

Case, A. (2001): "Does Money Protect Health Status? Evidence from South African Pensions." Princeton Manuscript.

Case, A. and A. Deaton (1998): "Large Cash Transfers to the Elderly in South Africa." Economic Journal, 108(September): 1330-1361.

Costa, D. (1997): “Displacing the Family: Union Army Pensions and Elderly Living Arrangements," Journal of Political Economy, 105(2), 1269-1292.

Costa, D. (1999): “A House of Her Own: Old Age Assistance and the Living Arrangements of Older Nonmarried Women," Journal of Public Economics, April, 72(1), 39-59.

DaVanzo, J. and A. Chan (1994): "Living Arrangements of Older Malaysians: Who Coresides with their Adult Children," Demography, 31(1), 95-113.

Duflo, E (2003): “Grandmothers and Granddaughters: Old Age Pensions and Intra-Household Allocation in South Africa." World Bank Economic Review, 17(1), 1-25.

Edmonds, E. (2002): " Reconsidering the Labeling Effect for Child Benefits: Evidence from a Transition Economy," Economics Letters 76(3), August 2002, 303-309 
Edmonds, E. (2003): “The Response of Child Labor Supply to Anticipated Income” Dartmouth College Manuscript.

Englehardt G., J. Gruber, and C. Perry (2002): “Social Security and Elderly Living Arrangements," NBER Working Paper \#8911, April.

Foster, A. (1993): "Household Partition in Rural Bangladesh." Population Studies. 47 (1993). 97-114.

Foster, A. (1999): “Altruism, Household Coresidence and Women's Health Investment in Bangladesh," Brown University Manuscript.

Foster, A. and Rosenzweig M. (2001): "Household Division and Rural Economic Growth." Review of Economic Studies, forthcoming.

Frankenberg, E., Smith, J., and Thomas D. (2003): "Economic Shocks, Wealth, and Welfare," Journal of Human Resources.

Grimard, F. (2000): "Rural Labor Markets, Household Composition, and Rainfall in Cote d'Ivoire." Review of Development Economics 4(1). 70-86.

Hoerger, T., G. Picone, and F. Sloan (1996): "Public Subsidies, Private Provisions of Care and Living Arrangements of the Elderly." Review of Economics and Statistics. 428-440.

Jensen, R. (2004): 'Do private transfers 'displace' the benefits of public transfers? Evidence from South Africa" Journal of Public Economics 88(1), 89-112.

Kinsella, K. and V. A. Velkoff: (2001): An Aging World: 2001, U.S. Census Bureau, Series P95/01-1. U.S. Government Printing Office, Washington, DC.

Lucas, R. E. B. and O. Stark (1985): "Motivations to Remit: Evidence from Botswana." Journal of Political Economy. 93(1). 901-918.

Lund, F. (1993): "State Social Benefits in South Africa." International Social Security Review 46(1) pp. 5-25.

Lundberg, S. and Pollak R. (1993): "Separate Spheres Bargaining and the Marriage Market." Journal of Political Economy. 101(2). 988-1010.

Lundberg, S., R. Pollak, and T. Wales (1997): "Do husbands and wives pool their resources? Evidence from the UK Child Benefit," Journal of Human Resources, 32(3), 463-80.

McGarry, K. and R. Schoeni (2000): "Social Security, Economic Growth, and the Rise in Independence of Elderly Widows in the 20th Century," Demography, 37(2), 221-236.

Michael, R., V. Fuchs, and S. Scott (1980): "Changes in the Propensity to Live Alone: 19501976," Demography, 17(1), 39-56.

Moultrie, T. A., and I. M. Timaeus (2002): "Trends in South African fertility between 1970 and 1998," Technical Report, Medical Research Council, South Africa. www.mrc.ac.za/bod/trends.pdf.

Pollak, R. (1994): "For better or worse: The roles of power in models of distribution within marriage," American Economic Review, 84(2), 148-52.

Porter, J. (2000): “Semiparametric Estimation of Regression Discontinuity Models," Harvard University Manuscript. November 2000. 
Rosenzweig, M. R. (1988): "Risk, Implicit Contracts, and the Family in Rural Areas of LowIncome Countries," The Economic Journal, 98(393), 1148-1170.

Rosenzweig, M. and O. Stark (1989): "Consumption Smoothing, Migration, and Marriage: Evidence from Rural India." Journal of Political Economy. 97. 905-926.

Statistics South Africa (No date (a)): "The Count And How It Was Done." (Census, Census '96, Methodology Reports and Meta-Data)

Statistics South Africa (No date (b)): "Sample (5a)." http://www.statssa.gov.za/ (Census, Census '96, Methodology Reports and Meta-Data)

Statistics South Africa (No date (c)): "Definitions." http://www.statssa.gov.za/ (Census, Census '96, Methodology Reports and Meta-Data)

Strauss, J. and D. Thomas (1995): "Human Resources: Empirical Modeling of Household and Family Decisions." in Handbook of Development Economics IIIA, J. Behrman and T. N. Srinivasan, eds. Elsevier: Amsterdam, 1883-2023.

Thomas, D. (1990): "Intra-household Resource Allocation, An Inferential Approach," Journal of Human Resources, 25(4), 635-664.

Thomas, D. (1994): “Like Father, Like Son; Like Mother, Like Daughter: Parental Resources and Child Height," Journal of Human Resources, 29(4), 950-988.

Thomas, D., E. Frankenberg, K. Beegle, and G. Teruel (1999): "Household budgets, household composition, and the crisis in Indonesia: Evidence from longitudinal household survey data." UCLA Manuscript.

Thomas, D. and Rubalcava, L. (2000): "Family Bargaining and Welfare," UCLA Manuscript.

Van der Berg, S. (2001): "Issues in South African Social Security." Stellenbosch Economic Working Paper, University of Stellenbosch Department of Economics. Reprint of World Bank Manuscript (May 1994).

Wolf, D. and B. Soldo (1988): "Household Composition Choices of Older Unmarried Women," Demography, 25(3), 387-403.

\section{Appendix A: Formal Retirement and the Pension Eligibility of Women}

Perhaps the most important identifying assumption of our methodology is the following: in the absence of the pension, family composition would change only smoothly (with respect to age) at age 60 for women. This assumption would be violated, for example, if other institutional features in the South African economy induced changes in family composition at these ages. One such institution would be incentives in the formal work sector that induce retirement at age 60 for women. If these institutions are prevalent, we will confound the impacts of the pension with the impacts of these other institutions.

We are unable to look directly at retirement patterns at the eligibility ages because the pension itself is likely to induce retirement. For example, the pension income may enable an elder female to stop working. This in turn may change her preferences for family composition. This type of retirement effect is not an identification problem for this paper - indeed, this is part 
of what we hope to capture. Instead, we are concerned about the possibility that, in the absence of the pension, retirement would largely occur at pension ages.

We cannot test directly for this in our data because of the above-mentioned direct effects of the pension on elderly retirement. However, several points suggest that in practice the problem is minor for women pensioners. First, most black South Africans are not engaged in formal employment that would have a fixed retirement age. This is especially true for women, most of whom report no income prior to receiving the pension (Panel A of figure 1). Second, most black South Africans are sufficiently poor that they do not have the luxury of terminating employment at a specified age (in the absence of the pension). This has been found consistently in other low income countries (e.g. Cameron and Cobb-Clark 2001, Benjamin, Brandt, and Fan 2003). Typically, poor health and other problems associated with aging force the elderly out of employment, but there is no reason why we should expect health shocks for women at 60 versus 59 or 61.

In order to examine the extent of formal retirement issues, we compare the retirement patterns of elder women who are likely affected by formal retirement to those that are not. First, we classify workers into two groups: those we think are very unlikely to have formal retirement incentives (workers in agriculture, fisheries, or what the South African Census classifies as "elementary occupations ${ }^{21}$.") We then compare these workers' retirement patterns around the ages of pension eligibility against those in the other industries which are more likely to be formal. We hypothesize that formal retirement should only affect individuals engaged in formal work, while both formal and informal workers should experience the retirement induced by the pension program. Thus, we use the change in work that we observe in the informal sector as a baseline to compare to the change in work that we observe in the formal sector where formal retirement is more likely. If the pension affects formal and informal workers similarly, then any extra change that we observe in the formal sector could be attributed to formal retirement.

In the our sample, 12.6 percent of black women aged 59 are working in what we have defined as informal work and are hence unlikely to face formal retirement (only 19 percent of black women are working at age 59, so 66 percent of these participate in informal work). The fraction of women in informal work declines to 6.7 percent of the population by age 61 . This represents a relative decrease of 47 percent. For women who are working in occupations potentially subject to formal retirement, we observe a drop from 6.5 percent of the population aged 59 to 3.9 percent of the population aged 61, a relative decrease of 40 percent. Thus, formal retirement is not likely to be a serious complication in our results when women become pension eligible, because we observe similar declines in employment in both formal and informal groups. Our calculations for men at pension eligibility were less encouraging, and thus we restrict our attention in this paper to the pension eligibility of women.

\section{Appendix B: Regression Discontinuity Results for all Age-Sex Groups}

\footnotetext{
${ }^{21}$ Three subcategories of elementary occupations are listed in the Census documentation: Sales and services elementary occupations; Agricultural, fishery and related labourers; and Labourers in mining, construction, manufacturing, and transport. However, we reclassify anyone in this category who also reports their industry as mining as engaged in possibly formal work.
} 
We examine changes in household composition by looking at changes in the presence of females and males in age groupings 0 to 5,6 to 11,12 to 17,18 to 23,24 to 29,30 to 39 and 40 to 49 . To present this information succinctly, we change our presentation slightly. We create a set of gender - age group counts and run a series of regressions (still using Porter's methodology) to estimate the change in that gender - age group count associated with female pension eligibility. For example, we estimate the impact of women's pension eligibility on the number of girls 0-5 in the household. Then, we estimate the impact of eligibility on the number of girls 611 and so on through age group 40-49. We repeat this process to estimate the impact of pension eligibility for the same age groups for males.

The by age group changes in the number of females associated with the pension eligibility of a woman are in figure 7 . The points labeled $M$ indicate the estimated change in the number of men for each group, and the points labeled $F$ indicate the estimated changes in women. Each point in the figure represents an estimate of $\alpha$ in (2) from one regression. Thus, the point $(\mathrm{X}, \mathrm{Y})$ has the interpretation of "the number of $\mathrm{X}$-year old females in the household increases by $\mathrm{Y}$ as a woman becomes pension eligible." 95 percent confidence intervals for the estimated change in the number of co-resident persons in each group are also pictured in figure 7.

To aid interpretation, we present these results in slightly different form in Figure 8 . Since the distribution of ages in the population is not perfectly uniform, the results would be easier to interpret if expressed as percentage changes. Hence, in figure 8 , we present confidence intervals and point estimates for the semi-elasticities calculated by dividing the discontinuity estimate by the mean number of individuals in a given gender - age group that are co-resident with elderly women at the age of pension eligibility. Using the notation of (2), the y-axis in figure 8 is:

$\frac{\hat{\alpha}}{\hat{m}(\text { AgeofPensionEligiblilty })}$.

Thus, the semi-elasticities in figure 8 are based on the estimates of $\alpha$ pictured in figure 7 and the corresponding estimates of $\hat{m}$ (AgeofPensionEligiblilty).

There are two main changes when women become pension eligible. First, the number of 0-5 year olds (the magnitude of the effect and the statistical significance is greater for boys than girls) and 18-23 year olds (both sexes) increase. ${ }^{22}$ As noted in the text, the rise in 18-23 year old women and $0-5$ year olds is likely to be related. It is possible that the increase in young men is also related to the increase in young women, in that they may be partners. Second, the number of women 30-39 and of men 40-49 decrease.

\section{Appendix C: Regression Discontinuity Results for Non-movers}

Our primary results identify the impact of pension eligibility on the household composition of elder women. However, we are unable to determine directly if these changes are due to family members moving in with (or away from) the elderly, or if the elderly themselves

\footnotetext{
${ }^{22}$ The statistical significance of the results for men 18-23 is not robust to using the bootstrapped standard errors discussed in footnote 11 .
} 
are changing location. One way we can shed light on this issue is to examine changes in the household composition for the elderly who do not move.

To study whether our results hold true for the non-migratory elderly, we re-estimate selected models conditioning on those elderly who live in rural settings and who do not report moving within the past seven years. This selection drops approximately one half of the observations used in the text. Results from estimating our main models on this sample are in table 4.

When we consider the household composition results, we find that they are robust to conditioning on rural non-movers. Again, total household size does not seem to change, nor does the propensity to live independently. Pension eligibility is also associated with large increases in the number of children 0-5 and women 18-23, and decreases in the number of women 30-39. Overall, the migration of the elderly does not appear to be the driving force behind our results. Instead, the observed changes in household composition appear to reflect movements around the elderly rather than movements of the elderly. 
Table 1:

Household Characteristics

\begin{tabular}{lcc}
\hline \hline Variable & Women aged 50-59 & Women aged 60-69 \\
\hline \hline \# Individuals - unweighted & 74,211 & 63,084 \\
Age & 54.3 & 64.1 \\
& $(2.8)$ & $(2.8)$ \\
Household size & 5.74 & 5.90 \\
& $(3.18)$ & $(3.31)$ \\
\# kids 0-5 in HH & 0.74 & 0.82 \\
& $(1.02)$ & $(1.08)$ \\
\# women 18-23 in HH & 0.41 & 0.34 \\
\# men 18-23 in HH & $(0.65)$ & $(0.61)$ \\
& 0.35 & 0.29 \\
\# women 30-39 in HH & $(0.61)$ & $(0.57)$ \\
& 0.22 & 0.30 \\
\# men 30-39 in HH & $(0.49)$ & $(0.56)$ \\
\hline \hline
\end{tabular}

Standard deviations in parentheses. All means are weighted to be representative of the black headed population of households in South Africa. All data are from the 1996 population census, black women living in black headed households.

Table 2: Regression Discontinuity Estimates of the Effect of Pensions on Independent Living

\begin{tabular}{lrl}
\hline \hline Variable & Effect & {$[\mathrm{mean}]$} \\
\hline \hline Household size & 0.085 & {$[5.82]$} \\
& $(1.51)$ & \\
Lives Alone & -0.002 & {$[0.05]$} \\
& $(0.44)$ & \\
Lives alone or with spouse only & 0.005 & {$[0.08]$} \\
& $(0.99)$ & \\
\hline \hline
\end{tabular}

T-statistics in parentheses. RD estimates of treatment effects estimate the jump in household size associated with turning 60 for women. RD methodology based on Porter (2000), as discussed in text. Conditional mean at treatment age of LHS variable in brackets. Data are from the 1996 census, black individuals living in black headed households. Estimates are based on $10 \%$ census samples, with 53,834 observations having nonzero weight in estimation of treatment effect. 
Table 3: Regression Discontinuity Estimates of the Effect of Pensions on Household Composition

\begin{tabular}{lcc}
\hline \hline Variable & Effect & {$[$ mean $]$} \\
\hline \hline \# kids 0-5 & 0.051 & {$[0.78]$} \\
& $(2.80)$ & \\
\# women 18-23 & 0.041 & {$[0.35]$} \\
& $(3.75)$ & \\
\# women 30-39 & -0.038 & {$[0.31]$} \\
& $(4.03)$ & \\
Births in HH in past year & -0.006 & {$[0.09]$} \\
\end{tabular}

T-statistics in parentheses. RD estimates of treatment effects estimate the jump in household size associated with turning 60 for women. RD methodology based on Porter (2000), as discussed in text. Conditional mean at treatment age of LHS variable in brackets. Data are from the 1996 census, black individuals living in black headed households. Estimates are based $10 \%$ census samples, with 53,834 observations having nonzero weight in estimation of treatment effect.

Table 4: Regression Discontinuity Estimates for Non-migrant Women Pensioners Conditioning on not moving within 7 years and living in Rural area

\begin{tabular}{lrc}
\hline \hline Variable & Effect & {$[$ mean] } \\
\hline \hline Household size & 0.003 & {$[6.09]$} \\
& $(0.05)$ & \\
Lives alone & -0.001 & {$[0.04]$} \\
& $(0.13)$ & \\
Lives alone or with spouse & 0.006 & {$[0.06]$} \\
& $(1.09)$ & \\
\# kids 0-5 & 0.069 & {$[0.89]$} \\
& $(2.62)$ & \\
\# women 18-23 & 0.034 & {$[0.37]$} \\
& $(2.82)$ & \\
\# women 30-39 & -0.034 & {$[0.26]$} \\
\end{tabular}

T-statistics in parentheses. RD estimates of treatment effects estimate the jump in household size associated with turning 60 for women. RD methodology based on Porter (2000), as discussed in text. Conditional mean at treatment age of LHS variable in brackets. Data are from the 1996 census, black individuals living in black headed households. Estimates are based on $10 \%$ census samples, with 35,496 observations having nonzero weight in estimation of treatment effect. 


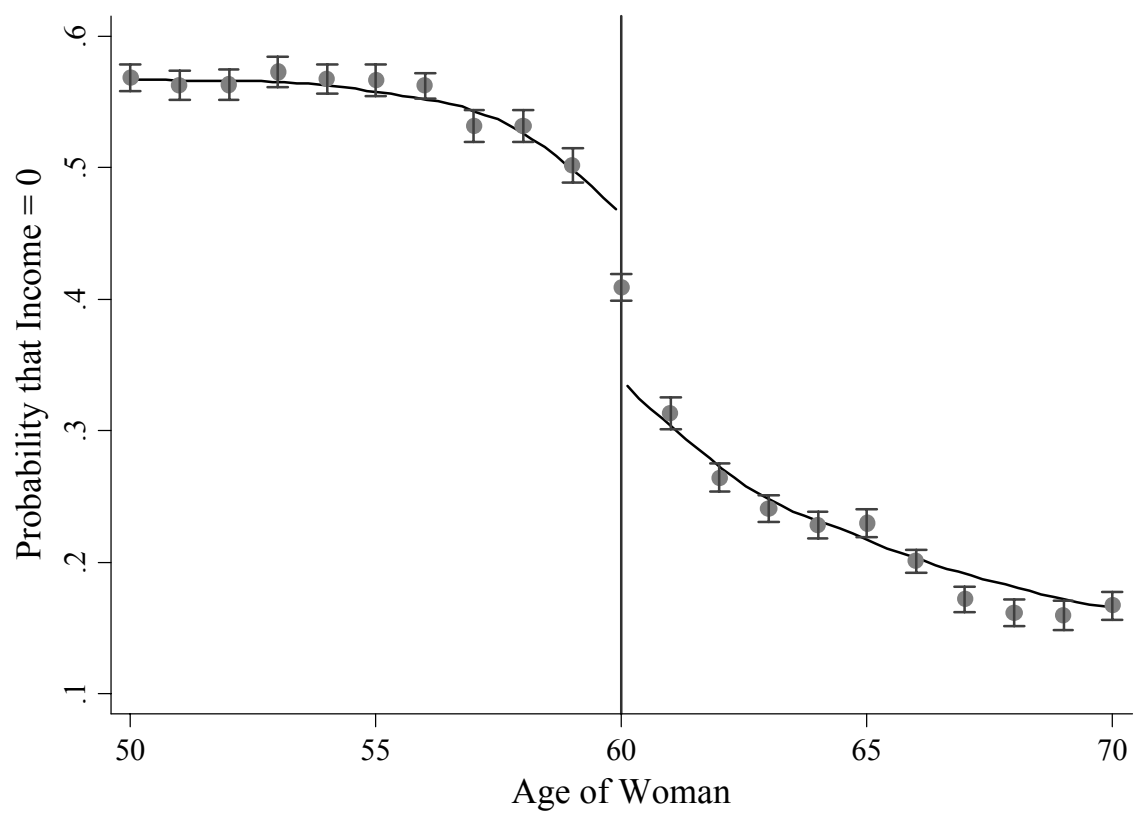

Estimate of Discontinuity (alpha) $=-0.125$, T-statistic $=15.27$

\section{Panel A}

Probability that an individual reports no personal income

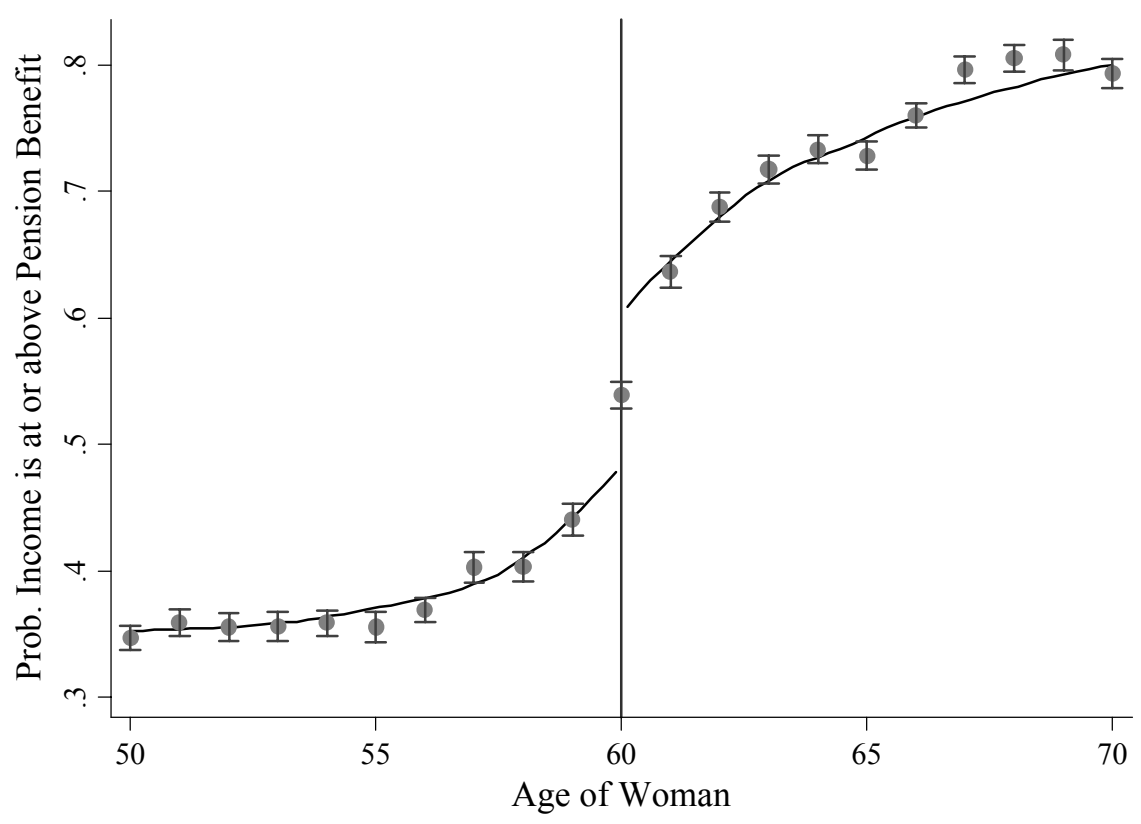

Estimate of Discontinuity (alpha) $=0.120$, T-statistic $=14.50$

\section{Panel B}

Probability that income is at least 200 Rand per month

\section{Figure 1}

Income and Pension Eligibility, Census Means and Regression Discontinuity Results 


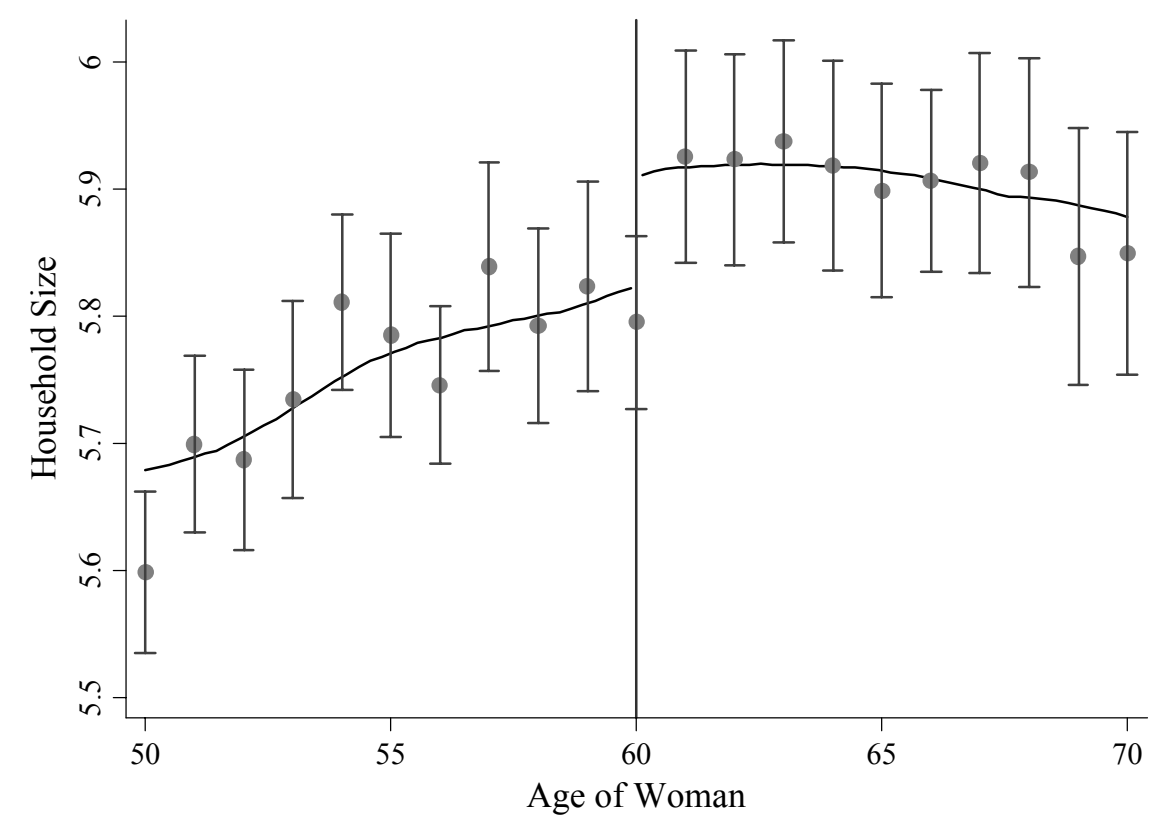

Estimate of Discontinuity (alpha) $=0.085, \mathrm{~T}$-statistic $=1.51$

\section{Figure 2}

Household Size and Pension Eligibility, Census Means and Regression Discontinuity Results

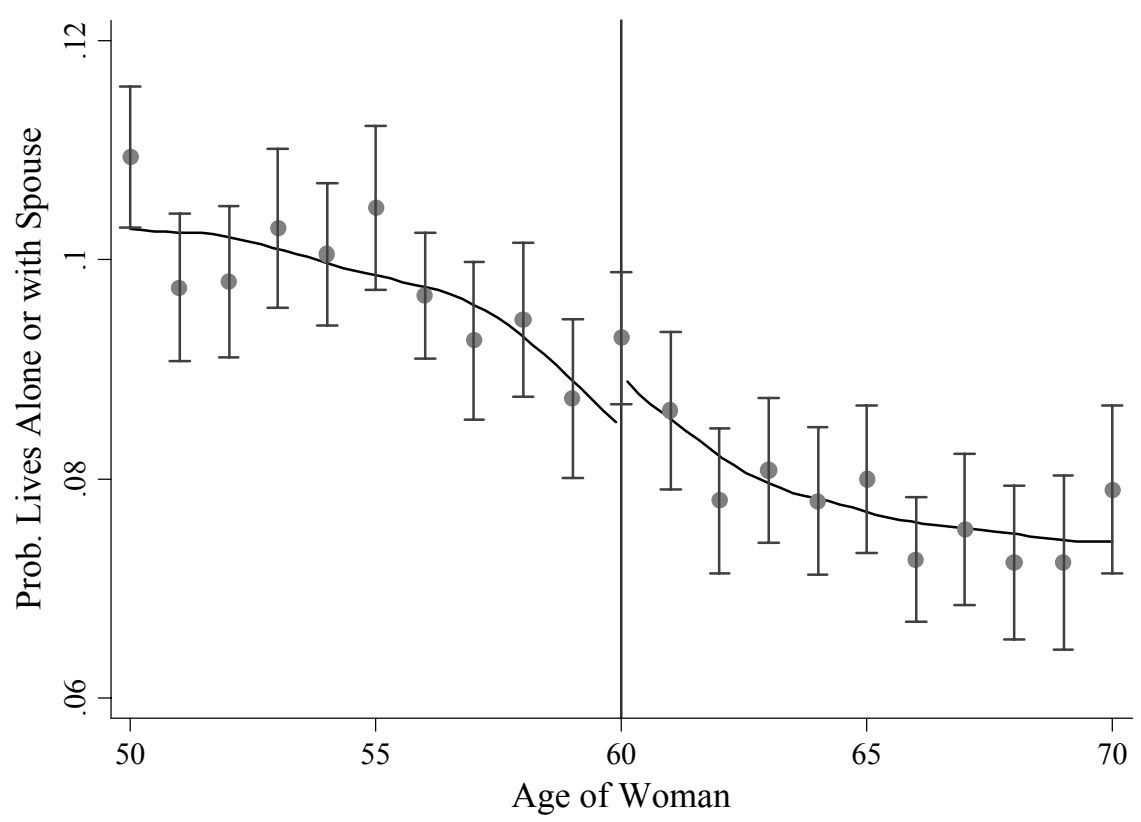

Estimate of Discontinuity (alpha) $=0.005$, T-statistic $=0.99$

\section{Figure 3}

The probability of living alone or only with spouse and Pension Eligibility, Census Means and Regression Discontinuity Results 


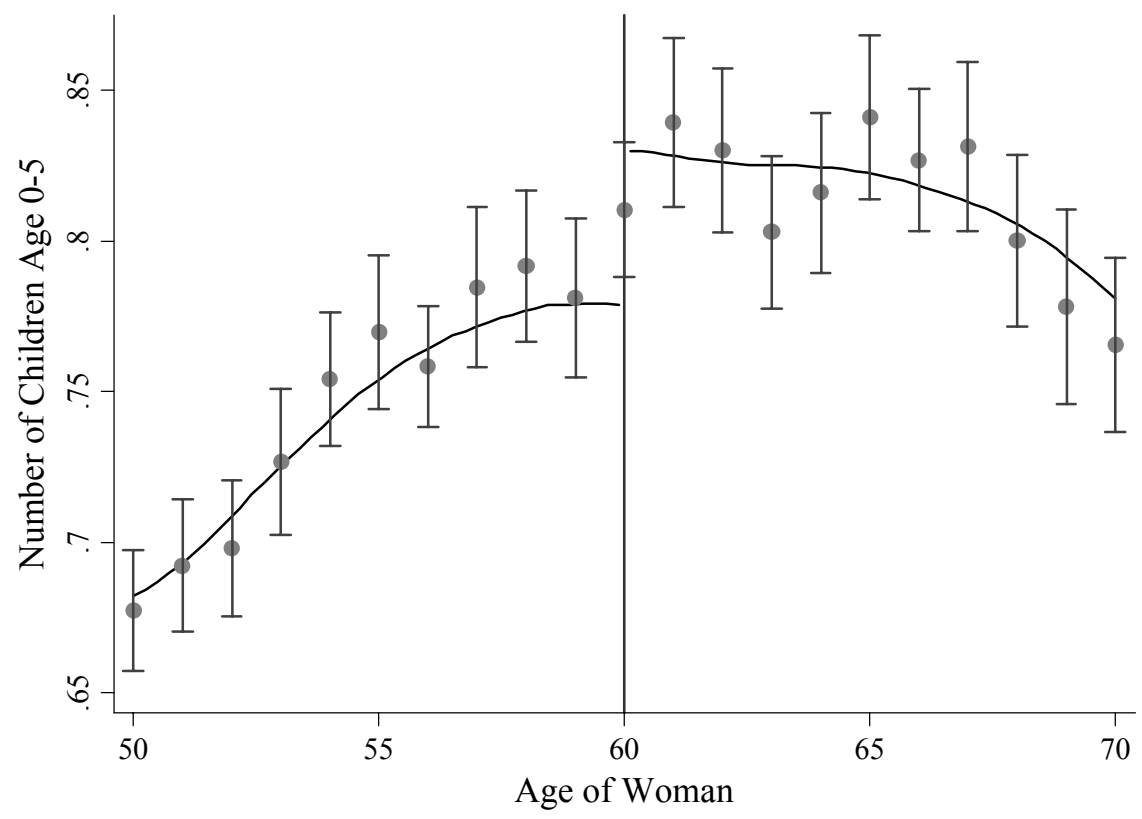

Estimate of Discontinuity (alpha) $=0.051$, T-statistic $=2.80$

\section{Figure 4}

The number of resident children age 0-5 and pension eligibility, Census Means and Regression Discontinuity Results

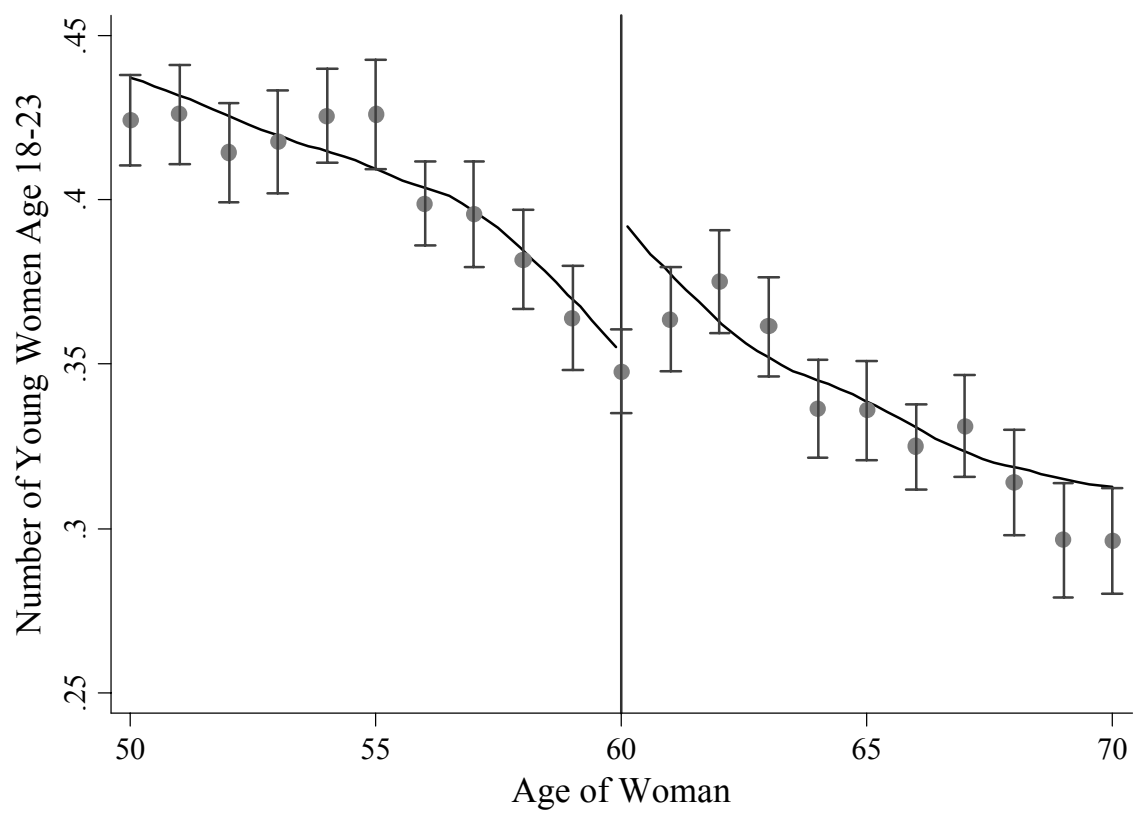

Estimate of Discontinuity (alpha) $=0.041$, T-statistic $=3.75$

\section{Figure 5}

The number of resident women 18-23 and pension eligibility, Census Means and Regression Discontinuity Results 


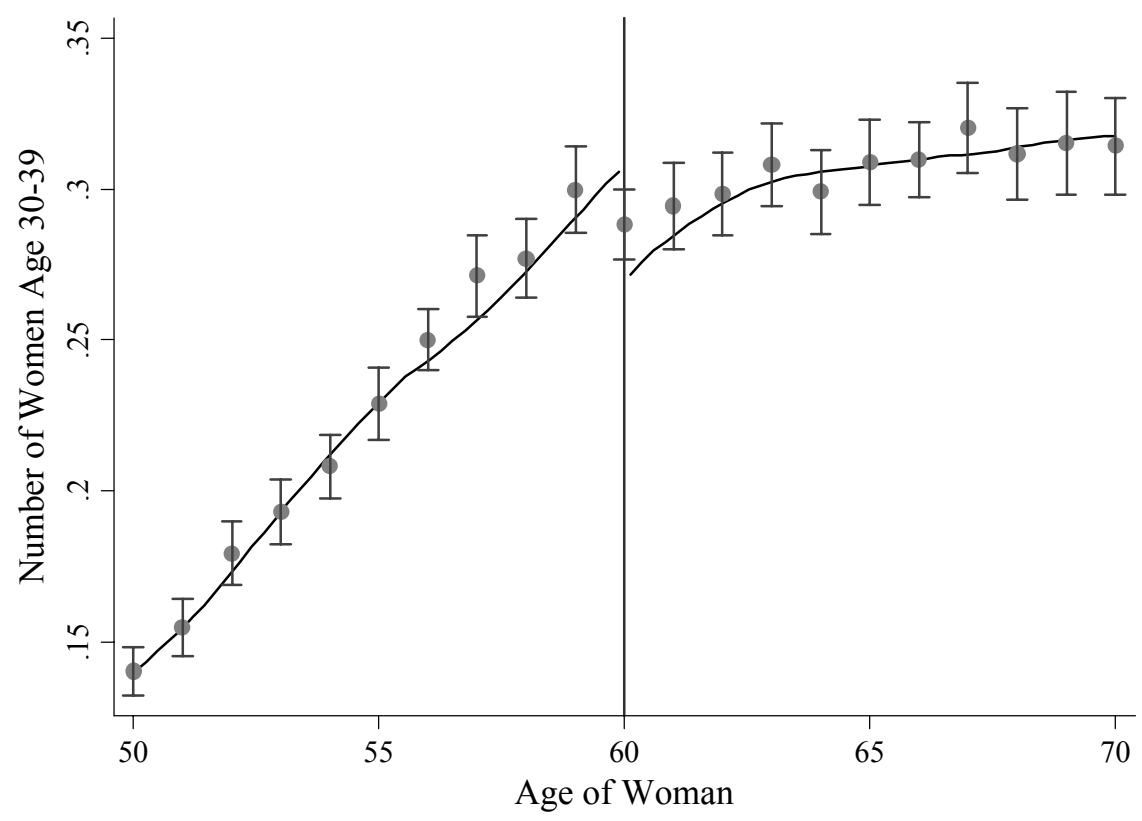

Estimate of Discontinuity (alpha) $=-0.038$, T-statistic $=4.03$

\section{Figure 6}

The number of resident women 30-39 and pension eligibility, Census Means and Regression Discontinuity Results

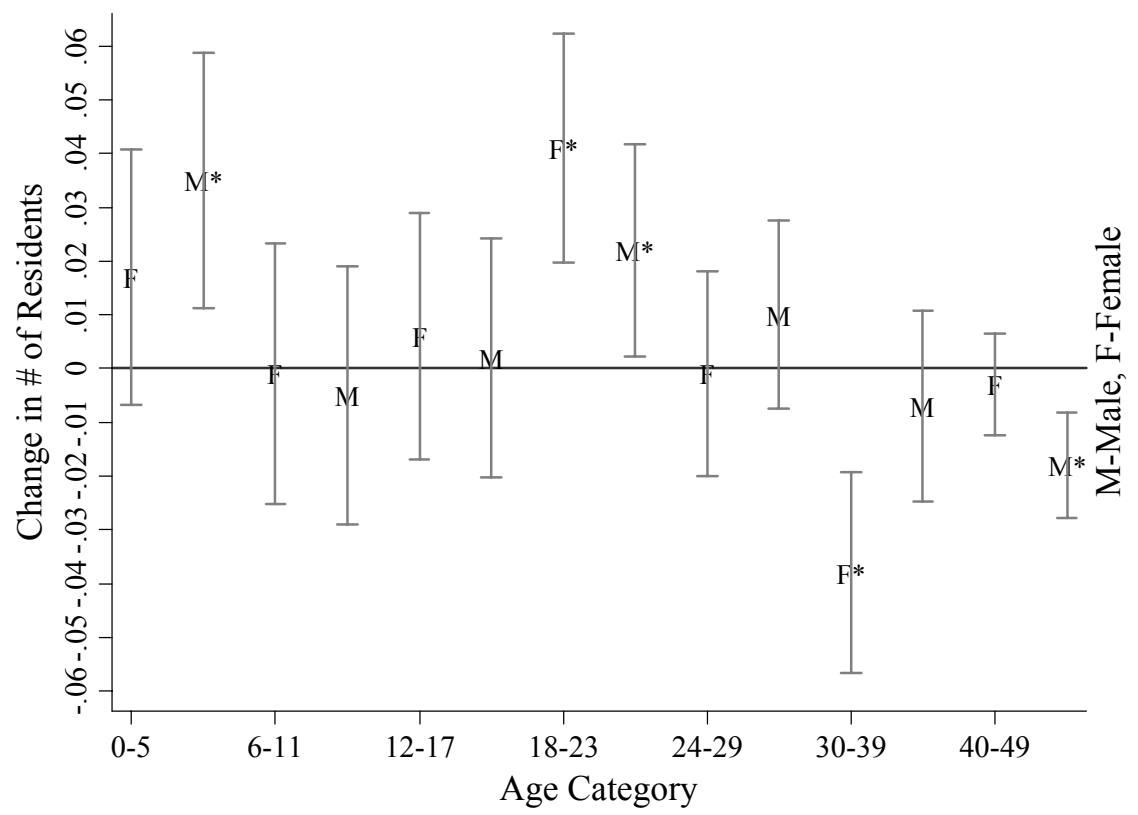

* Significant at 95\%. 95\% confidence intervals are pictured

\section{Figure 7}

Age-by-age changes in the number of resident females and males when a woman becomes pension eligible at age 60 , regression discontinuity results 


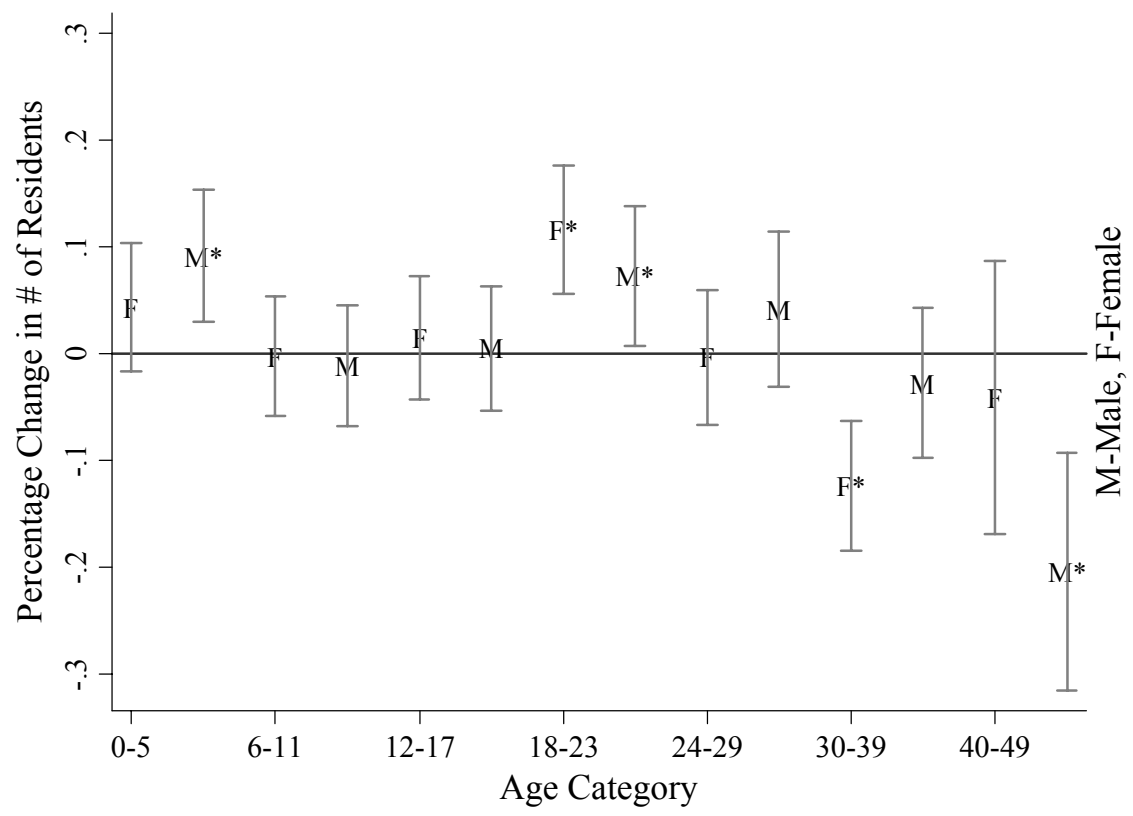

* Significant at 95\%. 95\% confidence intervals are pictured

\section{Figure 8}

Age-by-age percentage changes in the number of resident females and males when a woman becomes pension eligible at age 60, regression discontinuity results 